\title{
Factors hindering the implementation of surgical site infection control guidelines in the operating rooms of low-income countries
}

Citation for published version (APA):

Khan, M. N. A., Verstegen, D. M. L., Bhatti, A. B. H., Dolmans, D. H. J. M., \& van Mook, W. N. A. (2018). Factors hindering the implementation of surgical site infection control guidelines in the operating rooms of low-income countries: a mixed-method study. European Journal of Clinical Microbiology \& Infectious Diseases, 37(10), 1923-1929. https://doi.org/10.1007/s10096-018-3327-2

Document status and date:

Published: 01/10/2018

DOI:

10.1007/s10096-018-3327-2

Document Version:

Publisher's PDF, also known as Version of record

\section{Document license:}

Taverne

Please check the document version of this publication:

- A submitted manuscript is the version of the article upon submission and before peer-review. There can be important differences between the submitted version and the official published version of record.

People interested in the research are advised to contact the author for the final version of the publication, or visit the DOI to the publisher's website.

- The final author version and the galley proof are versions of the publication after peer review.

- The final published version features the final layout of the paper including the volume, issue and page numbers.

Link to publication

\footnotetext{
General rights rights.

- You may freely distribute the URL identifying the publication in the public portal. please follow below link for the End User Agreement:

www.umlib.nl/taverne-license

Take down policy

If you believe that this document breaches copyright please contact us at:

repository@maastrichtuniversity.nl

providing details and we will investigate your claim.
}

Copyright and moral rights for the publications made accessible in the public portal are retained by the authors and/or other copyright owners and it is a condition of accessing publications that users recognise and abide by the legal requirements associated with these

- Users may download and print one copy of any publication from the public portal for the purpose of private study or research.

- You may not further distribute the material or use it for any profit-making activity or commercial gain

If the publication is distributed under the terms of Article 25fa of the Dutch Copyright Act, indicated by the "Taverne" license above, 


\title{
Factors hindering the implementation of surgical site infection control guidelines in the operating rooms of low-income countries: a mixed-method study
}

\author{
Muhammad Nasir Ayub Khan ${ }^{1}$ (D) - Daniëlle M. L. Verstegen ${ }^{2}$ - Abu Bakar Hafeez Bhatti ${ }^{3} \cdot$ Diana H. J. M Dolmans $^{2}$. \\ Walther Nicolaas Anton van Mook ${ }^{4}$
}

Received: 23 May 2018 / Accepted: 10 July 2018 / Published online: 10 August 2018

(C) Springer-Verlag GmbH Germany, part of Springer Nature 2018

\begin{abstract}
The study aims to find the factors hindering the implementation of surgical site infection control guidelines in the operating rooms of low-income countries. The design of the study is a mixed-method sequential explanatory study. The setting is Shifa International Hospital and Pakistan Institute of Medical Sciences, Islamabad, Pakistan. Participants are health care workers. A questionnaire and structured key informant interviews probed the perspectives and perceptions of different stakeholders regarding the factors which hinder the implementation of surgical site infection control guidelines. Two-hundred fifty-two health care workers took part in the survey. The response rate was $90 \%$. The majority of the participants was based in private teaching hospitals $(63.9 \%)$ and $36.1 \%$ in the public sector teaching hospitals. The factors of surveillance, knowledge, education, and culture had low scores. Qualitative data analysis revealed the hindering factors in the implementation of surgical site infection control guidelines in the operating rooms of low-income country. The important one are lack of a surveillance system, education, and culture of infection control. This study identified hindering factors regarding implementation of surgical site infection control guidelines in the operating rooms at the institutional and individual level involved in patient care. The identification of these hindering factors may help politicians, policy makers, and institutions to identify the strategies for overcoming these hindering factors. Education is the key factor for success. By offering training to health care workers, we significantly contribute to decrease the incidence of SSIs in the low-income country.
\end{abstract}

Keywords Surgical site infections $\cdot$ Hindering factors $\cdot$ Low-income country $\cdot$ Evidence base guidelines $\cdot$ ORs

Electronic supplementary material The online version of this article (https://doi.org/10.1007/s10096-018-3327-2) contains supplementary material, which is available to authorized users.

Muhammad Nasir Ayub Khan

drmnasirayubk@gmail.com

Daniëlle M. L. Verstegen

d.verstegen@maastrichtuniversity.nl

Abu Bakar Hafeez Bhatti

abubakar.hafeez@yahoo.com

Diana H. J. M Dolmans

d.dolmans@maastrichtuniversity.nl

Walther Nicolaas Anton van Mook

w.van.mook@mumc.nl
1 Department of Health Professions Education, Shifa International Hospital and Shifa Tameer-e-Millat University, Islamabad, Pakistan

2 School of Health Professions Education, Maastricht University, Maastricht, Netherlands

3 Department of Liver Transplantation, Shifa International Hospital, Islamabad, Pakistan

4 School of Health Professions Education, Maastricht University Medical Centre+ and Maastricht University, Maastricht, Netherlands 


\section{Introduction}

Establishment of high-quality clinical practice in any given health care system requires vigilance, dedication, and adherence to a strict ethical and professional code of conduct [1]. Especially in low-income countries challenges include, for example, weak health care systems, poor professional regulation, lack of access to evidence-based guidelines, lack of infrastructure for training, and continuing professional development $[1,2]$. However, European and North American institutes are not an exception in this regard as patients remain deprived of appropriate medical care based on evidencebased knowledge. For example, poor compliance with antibiotic prophylaxis protocol in gastrointestinal surgery has been reported across three UK hospitals [3]. Similarly, poor compliance with appropriate timing of prophylactic antibiotic administration [4] was associated with increase rate of surgical site infections (SSIs), i.e., infection of incisions, organ, and space after surgical intervention [5] across surgical specialties in USA. Thus, patients received suboptimal preoperative antibiotic prophylaxis is that potentially harmed the patient and contributed to the wastage of resources.

These examples illustrate the gap between what is known and what we practice. The 2004 World Report on knowledge for better health stated that scientific discoveries can improve people's health only if they are applied properly in health care systems [6]. This report emphasize on translating knowledge into action, thereby bridging the gap between knowledge and what is actually done in practice [6]. However, the increasing volume of evidence on how to treat patients makes it difficult for health care workers (HCWs), especially the doctors, nurses, and technologists working in operating rooms, to keep up to date. This widens the gap between what is known about best clinical practice and how medical care is actually provided. Evidence-based guidelines can be an important tool to bridge the gap between knowledge and practice [7]. However, the development and publishing such guidelines do not assure that they will get implemented [6]. The so called "spray and pray" approach refers to the top to bottom approach in which the top managements accept guidelines and assume that they become implemented automatically. Acceptances at top level thus do not ensure their use in daily practice [7]. The implementation of evidence-based guidelines needs active involvement of HCWs, thus benefits from a bottom up approach to integrate and implement guidelines at the meso- and micro-level.

To summarize, implementation of evidence-based guidelines for prevention of SSI and promoting compliance on the part of HCWs working in the operating rooms (ORs) have been suggested as an efficient means to reduce the incidence of SSIs [8]. However, especially low-income countries face challenges regarding the use of evidence-based guidelines. In order to design effective educational interventions regarding
SSI control, further analysis of what factors hinder the implementation guidelines to reduce SSIs in low-income countries is required.

We designed a study to explore the factors which hinder the implementation of SSI control guidelines in ORs of a lowincome country, Pakistan, based on the following research questions.

\section{Research questions}

1. To what extent are SSI control guidelines applied effectively in the ORs of low-income countries and to what extend do the different stakeholders perceive to have sufficient knowledge?

2. What are the perspectives and perceptions of different stakeholders regarding the factors which hinder the implementation of SSI guidelines in the ORs in low-income countries?

\section{Methods and setting}

Study design A mixed-method sequential, two-phase explanatory study was conducted. In the first phase, a questionnaire was used to evaluate the factors that affect the effectiveness of the WHO Global Guidelines 2016 for prevention of SSIs in the ORs. In the second phase, structured interviews were conducted with leaders of HCWs working in the ORs to find out perspectives and perceptions of different stakeholders regarding the factors which hinder the implementation of SSI guidelines control guidelines in the ORs in low-income countries.

Settings Two teaching hospitals, Shifa International Hospital in a private sector and Pakistan Institute of Medical Sciences, Islamabad, in the public sector with anticipated deep insights in the factors which hinder the effectiveness of SSI guidelines in the ORs of low-income country were chosen for the study.

Participants The questionnaire was distributed to collect quantitative data from $280 \mathrm{HCWs}$ working in the ORs of the two hospitals. Participants for interviews were purposefully selected from stakeholders with roles in ORs, including members of the infection control team, operating room managers, nurses, technologist, surgeons, and anesthesiologists. Informed consent was obtained verbally before the start of interviews, and interviews were continued until saturation in analysis was reached. All interviews were digitally recorded. The participants had the option of withdrawing at any time for any reasons. Only the researchers had access to the digital recordings and the data were stored in data verse. 


\section{Ethical approval}

Approval by the ethical committee of Shifa Tameer-e-Millat University was acquired (IRB number 760-035-2017).

\section{Questionnaire}

A questionnaire was used to explore the factors which affect the effectiveness of SSI guidelines in the ORs of a low-income country $[9,10]$. The questionnaire consisted of 51 closed items related to seven categories of barriers (items related to education and culture were added to questionnaire): factors related to surveillance (4 items), knowledge (3 items), and education (5 items); skills related to safe injections and point of care devices (11 items); and skills related to sterilization and high-level disinfection (12 items), culture (5 items), and cleaning of operating rooms (6 items). The respondents were asked to indicate their agreement using a 6-point Likert scale, ranging from strongly agree (5), agree (4), somewhat agree (3), somewhat disagree (2), disagree (1) to strongly disagree (0). The participants were approached directly by the researcher.

\section{Interviews}

Key interviews were conducted to explore stakeholders' perspectives and perceptions. The interview guide was prepared after review of literature and analysis of the results of the questionnaire. Each semi-structured interview (Appendix B) consisted of 11 questions which probed the factors which hinder the implementation of SSI control guidelines in the ORs. A sample of 12 interviews with participants was done. During the analysis, it became clear that this was enough to reach saturation.

\section{Data analysis}

The Statistical Package for the Social Sciences software package 22.0 was used for the analysis for quantitative data. Mean and standard deviation of each item was calculated. An item's specific barrier score was calculated as mean value. A score of 3.5 or higher on a scale from 0 to 5 was considered as high. A score below 3 was considered as insufficient, and a score in between 3 and $3 \frac{1}{2}$ as moderate, i.e., still needs some improvement. The item's specific score results in an overall score between 0 and 5 . The qualitative data was read independently by two authors (MNA and AHB), identifying common themes through the constant comparison method; applying generally accepted principles of primary, secondary, and tertiary coding; identifying trends; and using the common opinions expressed by the participants. The identified themes were independently coded, enabling us to compare between participants' responses. The generated codes were thereafter cross-checked by WvM and DV. All discrepancies were discussed until consensus was reached. Illustrated quotes are presented.

\section{Results}

The quantitative and qualitative results of this study are discussed consecutively.

\section{The quantitative results}

The perception of health HCWs regarding each factor of the questionnaire will consecutively be discussed in the sections below.

\section{Demographic and contextual data}

Two-hundred fifty-two HCWs working in ORs took part in the survey. The response rate was $90 \%$. The majority of the participants were based in private teaching hospital (63.9\%) and $36.1 \%$ in the public-sector teaching hospitals. Of the participants, $45.2 \%$ were males and $52.8 \%$ were females. The distribution of participants was doctors $(43.7 \%)$, nurses (32.5\%), technologists (22.6\%), and perfusionist (1.2\%).

\section{Factor and item analysis}

Table 1 shows the mean score and the standard deviation on the main factors surveillance, knowledge and education, culture, skills for sterilization, safe injection, and cleaning of ORs. The scores on the factors varied between 4.07 standard deviation ( $\mathrm{SD}=2.04)$ and $2.66(\mathrm{SD}=0.99)$. The highest mean scores were related to safe injection, although scores varied substantially given the high SD. The lowest mean factor scores were related to education, knowledge, and culture. Detail scores of each individual item are shown in Appendix A.

\section{Qualitative results}

Qualitative analysis resulted in identification of two categories of hindering factors in implementation of SSI guidelines in the ORs of low-income country, namely, the hindering factors at the institutional level and at the individual level. Illustrated quotes to underscore the findings are presented where applicable. An overview is shown in Fig. Fig. 1.

\section{Hindering factors in implementation of SSI guidelines at the institutional level}

The following are the hindering factors in implementation of SSI guidelines at the institutional level in ORs of low-income 
Table 1 Descriptive statistics per factor $(n=$ number of items per factor)

\begin{tabular}{llll}
\hline Factors & $\begin{array}{l}\text { Mean }(\mathrm{M}) \\
(0 \text { to5) }\end{array}$ & $\begin{array}{l}\text { Standard } \\
\text { deviation }(\mathrm{SD})\end{array}$ & $\begin{array}{l}\text { Number of } \\
\text { respondents }(\mathrm{N})\end{array}$ \\
\hline Surveillance $(n=4)$ & 3.13 & 1.09 & 252 \\
Knowledge $(n=4)$ & 2.74 & 1.12 & 252 \\
Education $(n=5)$ & 2.66 & 0.99 & 252 \\
Culture $(n=10)$ & 2.80 & 0.71 & 252 \\
Sterilization $(n=12)$ & 3.64 & 0.72 & 252 \\
Safe injection $(n=11)$ & 4.07 & 2.04 & 252 \\
Cleaning of operating rooms $(n=6)$ & 3.7 & 0.83 & 252 \\
\hline
\end{tabular}

country in order of importance based on the extent of discussion. Illustrative quotes are provided wherever applicable.

Education and training were frequently a topic of discussion, mostly in relation to implementation of guidelines to prevent SSIs. The participants in our study perceived that the administrative and financial support in public hospitals is insufficient to develop human resource to prevent SSI guidelines in ORs.

"Hospitals do not have the facility to provide training for the specific staff to prevent infection or to be sending abroad for training to acquire more knowledge that is why people are not well trained." (P5)

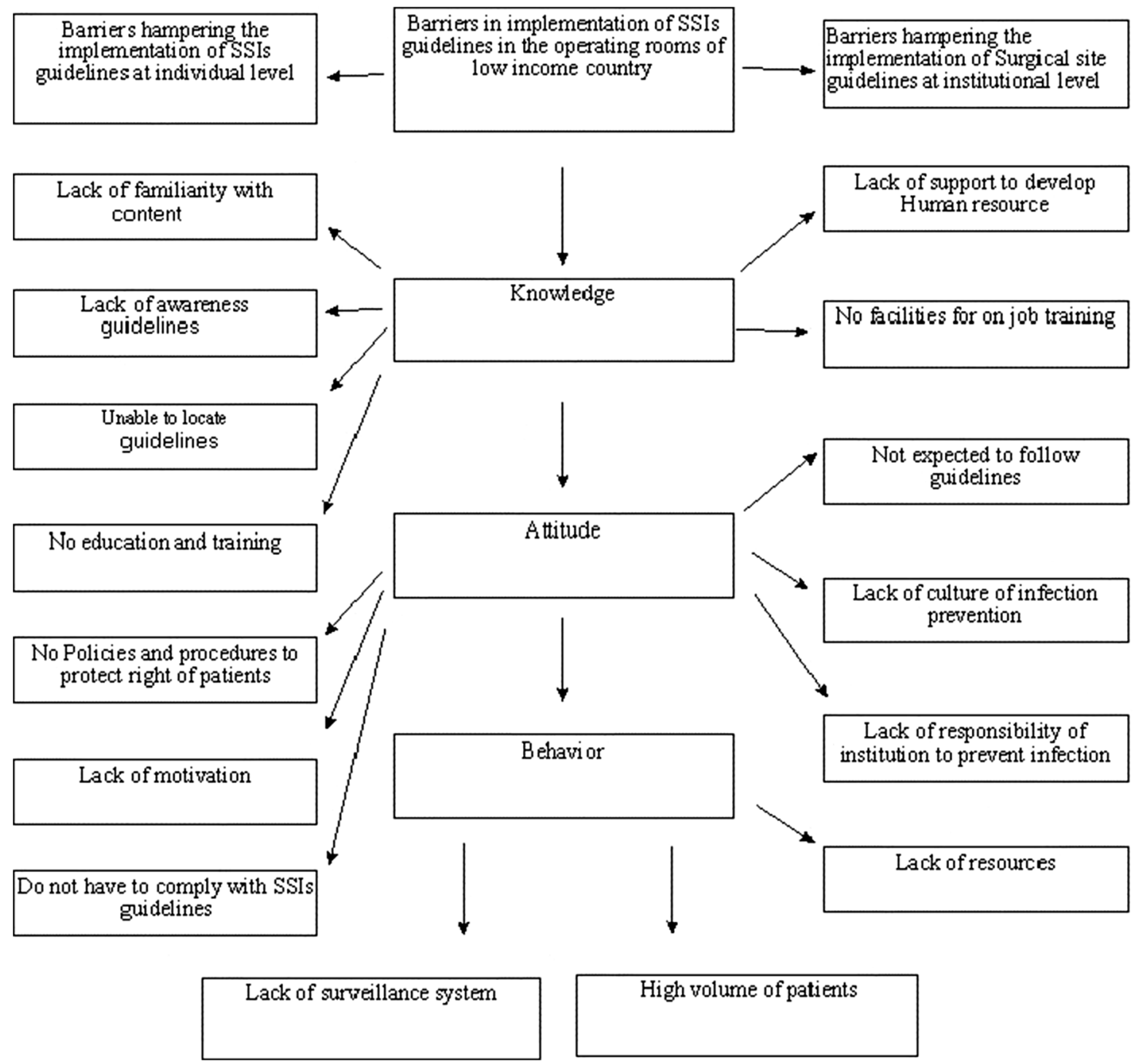

Fig. 1 Hindering factors in implementation of SSI guidelines in the operating rooms of low income country at the indivual level and institutional level 
The government health authorities do not have laws, policies, and rules in place to enforce guideline implementation to control SSIs.

"I think we can divide the barriers into two segments; Responsibility of the law enforcement agencies in the country and responsibility of health care institutions. I think both lack tremendously. Both do not have a clear idea what to do." (P4)

Many participants perceived that institutions do not create a culture of evidence-based practice by a coordinated effort to bring change through the use of best evidence.

"To be honest there is no such thing or you can say no proper intentions are there and maybe institutions do not care about it, I am not directly pointing toward anybody, but you know it well." (P5)

Some of the participants said the public sector hospitals are old, and ORs do not have proper air conditioning, clean water supply, adequate scrub areas, and regulation of traffic inflow.

"The buildings are old, have not been renovated for a long time, all the walls, structure including beds, and lights are quite old and need renovation. The buildings were not structured properly and not purpose belt." (P9)

\section{Hindering factors in implementation of SSI guidelines at the individual level}

The following are the hindering factors at the individual level in the ORs in order of importance based on the extent of discussion.

Inadequate knowledge and skills were intensively discussed as hindering factors in the implementation of SSI guidelines by all the participants. They discussed that HCWs working in the ORs do not have the education and training to prevent SSIs.

"There is a lack of knowledge, majority of the medics, have some idea about the safe surgical practice and specifically the infection control but still they might be lacking of knowledge which might be required to prevent the infection in the operating rooms." (P8)

Many participants are of the opinion that the HCWs are not aware of the importance of SSI guideline; therefore, they are not well prepared to apply the safety standards.
"People who have not seen how things are done in the West, cannot even comprehend how strict the policies are in Western countries, protecting the rights of the patient but in Pakistan that concept is not clear in the minds of the people." (P10)

In addition to the above, some of the participants consider that lack of acceptance to change as a barrier at an individual level.

"People they don't have acceptance. They don't want to change themselves. It is very hard to change mind for people in this society. So whatever their mind develops, they try to work accordingly." (P2)

\section{Discussion}

The results of this study provide an insight into the factors that hinder the implementation of SSI guidelines in the ORs of a low-income country. This mixed-method study has identified hindering factors for the implementation of SSI guidelines in the ORs at an institutional level and at an individual level of professionals involved in patient care. Both the quantitative and qualitative results show that participants believe that the lack of evidence-based culture to prevent SSIs coupled with weak education and poor surveillance system are the main hindering factors for the implementation of SSI guidelines in a low-income country. In addition to the above, the interview data revealed that governmental and health care institutions do not prioritize proper education and training to develop a culture of evidence-based practice to prevent SSIs. There is, therefore, a need to invest more in developing resources to train and educate HCWs in order to strengthen the implementation of SSI guideline.

The absence of surveillance systems for SSIs is the perceived second key hindering factor in implementation of SSI guidelines in the ORs of a low-income country. Surveillance of infection control is present in high-income countries, but not in most low-income countries [11]. However, without a functional surveillance system, it is not feasible for the ministry of health to monitor, evaluate, and document the real burden of infection at the national level. Therefore, an institutional and national surveillance system is at the heart of infection control. It not only identifies the problem but also defines the priorities for allocating funds to develop human resources, to prevent infection, and report lessons learnt regarding prevention of SSIs in the literature [11, 12]. Moreover, no policy exists to prevent SSIs in the ORs of low-income country at the national and institutional levels. These simple policies can decrease the incidence of SSIs. This lack of policy increases the socioeconomic burden of SSIs and pushes it in the spiral of weak health system of low-income countries [13]. 
This study also shows the gap between the available scientific knowledge in the form of SSI guidelines and practice among the HCWs working in the ORs. HCWs either lack the knowledge of guidelines or, if they have the required knowledge, they do not apply evidence-based guidelines to prevent SSIs in their practices. On the contrary, they seem to practice according to their personal beliefs. Therefore, proper education in the form of training and refresher courses is vital. It has been recognized that the fundamentals of infection control should be taught to all the HCWs [14]. However, no institute in Pakistan exists that can take care of training on preventing SSIs in the ORs, and this is true for other countries.

Similarly, the reasons behind the lack of implementation at an individual level in low-income countries are different from the developed part of the world. The individual hindering factors for instance lack of awareness, familiarity, and acceptance to follow SSI guidelines are the most common because HCWs working in ORs are usually not aware of Pakistan's national guidelines to control infection. Also, they are not familiar with the content of guidelines. Moreover, this study shows lack of organizational support for training at institutional level. The consequence is that hospitals do not have an adequate amount of trained personnel who can support implementation of SSI guidelines. This may be the reason that the participants of this study report that no culture of evidencebased practice exists. There is a general absence of policies, procedures, scientific guidelines, training material, and skills required to plan strategies to implement SSI guidelines.

Two studies from low-middle-income countries also reported the barriers in implementation of infection control practices on the individual and institutional level. The first study reported that staff turnover, time spent on training of new staff, limitations in language competence, and workload restraints are the major barriers to practice infection control in an Indian hospital [15]. The second study performed a gap analysis of infection control practice in six low-middle-income countries (Nepal, India, Argentina, Hungary, South Africa, and Greece) found that infection control practices are suboptimal in these counties because of limited infection control programs, limited surveillance of health-associated infections, lack of written policies, lack of procedures for sterilization of surgical instruments, and poor antibiotics stewardship and hand hygiene [13]. Furthermore, an international survey on infection control practices from members of society of health care epidemiology of America outside of USA and Canada (53\% members were from high, $43 \%$ members were middle, and $1 \%$ was from low-income countries) found that limited trained staff, infrastructure, and supplies were the major barriers to prevent multiple drug resistance organism transmission [16]. In these respects, our findings, thus in line with previous studies and barriers to implementation of infection control practice, are similar across the world.
To the best of our knowledge, this is however one of the first studies to specifically identify hindering factors behind the implementation of SSI guidelines in the OR of a lowincome country. The strength of this study is that it includes HCWs from different professional backgrounds working in private as well as public sector hospitals with high response rate of the participants. A limitation of this study is that the majority of the participants were working in private teaching hospitals and only one third of the participants in the public sector teaching hospitals, which could have influenced the findings. Respondents from private hospital may have responded differently because their institution is a joint commissioned accredited hospital which can take more measures to control SSIs as compared to public hospitals. Despite the fact that the overall response rate was high, the results may be non-generalizable to hospitals in the more remote areas of Pakistan. In addition, participation in the interviews took place on the basis of availability and willingness, so convenience sampling can be a limitation of this study. Finally, the study was limited to Pakistan, which is presumably representative for low-income countries, although political or other reasons may also limit the study's generalizability.

The results of this study serve as the first step in identifying the hindering factors to the implementation of SSI guidelines in the ORs of low-income countries. These results will help in designing interventions to narrow the gap between knowledge and practice of preventing SSIs. The results of this study may also stimulate researchers to corroborate the findings of this study in other low-income countries and to design additional studies addressing how to overcome these barriers in the ORs of low-income country. Based on the results of this study, the authors recommend that comprehensive low-cost educational modules on prevention of SSIs to be adopted by hospitals, which is feasible for hospitals with limited resources. Our future research will consequently focus on designing, implementing, and evaluation of such educational interventions.

\section{Conclusion}

This mixed-method study identified hindering factors at individual and institutional level regarding implementation of SSI guidelines in the ORs of low-income country. Lack of a surveillance system, education and training programs, and culture of evidence-based clinical practice are the major hindering factors identified in both the qualitative and quantitative data. The identification of these hindering factors may help politicians, policymakers, and institutions to identify the strategies and interventions for overcoming these hindering factors. Training is the key factor for success and can increase the knowledge and skills by offering training to health care professionals, and significantly contribute to decrease the incidence of SSIs in the low-income country. 


\section{Compliance with ethical standards}

Conflict of interest The authors declare that they have no conflict of interest.

Ethical approval My study has received ethical approval with reference number 760-035-2017 from IRB and EC of Shifa International Hospital.

Informed consent I also confirmed that written and verbal consent was taken and retained for future reference.

\section{References}

1. Garner P, Kale R, Dickson R, Dans T, Salinas R (1998) Getting research findings into practice: implementing research findings in developing countries. Br Med J 317:531-535

2. Ritchie LM, Khan S, Moore JE, Timmings C, van Lettow M, Vogel JP, Khan DN, Mbaruku G, Mrisho M, Mugerwa K, Uka S (2016) Low-and middle-income countries face many common barriers to implementation of maternal health evidence products. J Clin Epidemiol 76:229-237

3. Cameron M, Jones S, Adedeji O (2015) Antibiotic prophylaxis audit and questionnaire study: traffic light poster improves adherence to protocol in gastrointestinal surgery. Int J Surg 19:112-115

4. Velanovich V, Davila M (2017) Compliance with American College of Surgeons-NSQIP surgical site infection bundle and the occurrence of postoperative surgical site infections. J Am Coll Surg 225(4):e28

5. Berríos-Torres SI, Umscheid CA, Bratzler DW, Leas B, Stone EC, Kelz RR, Reinke CE, Morgan S, Solomkin JS, Mazuski JE, Dellinger EP (2017) Centers for Disease Control and Prevention guideline for the prevention of surgical site infection, 2017. JAMA surgery 152(8):784-791

6. Thamlikitkul V (2006) Bridging the gap between knowledge and action for health: case studies. Bulletin World Health Organization 84:603-607
7. van der Veer SN, Tomson C, Jager KJ, Van Biesen W (2013) Bridging the gap between what is known and what we do in renal medicine: improving implement ability of the European renal best practice guidelines. Nephrol Dial Transplant 29:951-957

8. World Health Organization (2016) Global guidelines for the prevention of surgical site infection. World Health Organization

9. Larson E (2004) A tool to assess barriers to adherence to hand hygiene guideline. Am J Infect Control 32:48-51

10. Bradley S (2013) Strategies to fully implement infection control practices in Pennsylvania ambulatory surgical facilities. Pennsylvania Patient Safety Authority 10:99-106

11. Swaminathan S, Prasad J, Dhariwal AC, Guleria R, Misra MC, Malhotra R, Mathur P, Walia K, Gupta S, Sharma A, Ohri V (2017) Strengthening infection prevention and control and systematic surveillance of healthcare associated infections in India. BMJ 358:j3768

12. Alp E, Damani N (2015) Healthcare-associated infections in intensive care units: epidemiology and infection control in low-tomiddle income countries. J Infect Dev Ctries 9(10):1040-1045

13. Weinshel K, Dramowski A, Hajdu Á, Jacob S, Khanal B, Zoltán M, Mougkou K, Phukan C, Staneloni MI, Singh N (2015) Gap analysis of infection control practices in low-and middle-income countries. Infect Control Hosp Epidemiol 36(10):1208-1214

14. Zingg W, Mutters NT, Harbarth S, Friedrich AW (2015) Education in infection control: a need for European certification. Clin Microbiol Infect 21(12):1052-1056

15. Barker AK, Brown K, Siraj D, Ahsan M, Sengupta S, Safdar N (2017) Barriers and facilitators to infection control at a hospital in northern India: a qualitative study. Antimicrob Resist Infect Control 6(1):35

16. Safdar N, Sengupta S, Musuuza JS, Juthani-Mehta M, Drees M, Abbo LM, Milstone AM, Furuno JP, Varman M, Anderson DJ, Morgan DJ (2017) Status of the prevention of multidrug-resistant organisms in international settings: a survey of the Society for Healthcare Epidemiology of America research network. Infect Control Hosp Epidemiol 38(1):53-60 